This item was submitted to Loughborough's Research Repository by the author.

Items in Figshare are protected by copyright, with all rights reserved, unless otherwise indicated.

\title{
Toughening of polymers by graphene
}

\section{PLEASE CITE THE PUBLISHED VERSION}

http://www.icevirtuallibrary.com/content/serial/nme

\section{PUBLISHER}

(C) ICE Publishing

\section{VERSION}

VoR (Version of Record)

\section{PUBLISHER STATEMENT}

This work is made available according to the conditions of the Creative Commons Attribution-NonCommercialNoDerivatives 4.0 International (CC BY-NC-ND 4.0) licence. Full details of this licence are available at: https://creativecommons.org/licenses/by-nc-nd/4.0/

\section{LICENCE}

CC BY-NC-ND 4.0

\section{REPOSITORY RECORD}

Wang, Xiao, and Mo Song. 2015. "Toughening of Polymers by Graphene”. figshare. https://hdl.handle.net/2134/17911. 


\section{Toughening of polymers by graphene}

$1 \quad$ Xiao Wang PhD

Department of Materials, Loughborough University, Loughborough, Leicestershire, UK
Mo Song PhD*

Department of Materials, Loughborough University, Loughborough, Leicestershire, UK

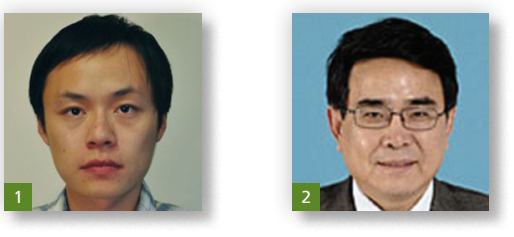

Graphene has been regarded as the next-generation carbon nanofiller for polymer nanocomposites. Owing to its superior physical properties, it produces a dramatic improvement in properties of polymers at very low filler loadings. In the past few years, toughening of polymers by graphene has been studied intensively. This article reviews the typical preparation methods of graphene and graphene/polymer nanocomposites. The authors summarize the enhancement effect, optimal filler loading and toughening mechanism for the polymer composites. Effects of some important factors including graphene content, thickness, sheet size, state and interfacial bonding with polymer chains have been addressed. Accordingly, the current challenges and future perspectives for the toughening of polymers by graphene are indicated.

\section{Introduction}

Due to the rapid development of nanoscience and nanotechnology in the past 20 years, improvement of polymer properties by nanofillers has become a vital topic in the field of material science. ${ }^{1-3}$ The polymer nanocomposites show enhanced properties by the incorporation of low amount of nanofillers such as carbon black $(\mathrm{CB})$, carbon nanotubes (CNTs), graphene and nanoclay. ${ }^{4-7}$ Due to the high surface to volume ratio and/or high aspect ratio, the nanofillers are more efficient than the traditional fillers in reinforcing polymers. ${ }^{8,9}$

Among the nanofillers, graphene is an atomically thick, 2D nanomaterial that is the strongest materials measured so far. ${ }^{10-12} \mathrm{It}$ possesses extraordinarily high Young's modulus, ${ }^{13}$ tensile strength, ${ }^{13}$ aspect ratio, ${ }^{3}$ surface area,${ }^{14}$ thermal conductivity ${ }^{15}$ and electrical conductivity. ${ }^{16}$ Since graphene was firstly achieved in $2004,{ }^{17}$ it has intensively attracted a great deal of interest in extensively exploring its applications. The superior properties of graphene also reflected in the graphene/polymer nanocomposites. It has been widely reported that the mechanical, thermal, electrical, gas-barrier and flame-retardant properties of polymer can be significantly improved by the addition of graphene..$^{3,6,18-24}$ Its advantages over other nanofillers have been discussed. ${ }^{3,19,25-28}$ However, the reinforcing efficiency of graphene highly depends on the dispersion and distribution of graphene sheets in the polymer matrix. ${ }^{29}$ An optimized graphene-polymer interface is critical in the property transfer. ${ }^{30-32}$ Pristine graphene sheets are not compatible with organic polymers and have a great tendency to agglomerate in the matrix. ${ }^{3,33,34}$ To resolve this problem, functionalization of graphene is an essential step to achieve a molecular level dispersion. ${ }^{3,35}$ The functionalized graphene (FG) sheets could form strong interfacial bonding with polymer chains, which is favorable for load transfer, but it also confines the motion of interfacial polymer segments. ${ }^{36-38}$ Thus, the enhancements in stiffness, tensile strength and hardness of polymer are frequently reported, while the elongation at break and ductility is always decreased., 3,6,39 Toughness of polymer is extremely important in the critical structural applications and highperformance areas such as automotive, aerospace and defence., ${ }^{9,40}$ Enhancing the toughness of polymer has been a challenging issue, especially for thermosets that have highly cross-linked structure. ${ }^{9}$ Traditional fillers, such as rubber particles, can improve the toughness, but they show negative impact on mechanical properties and manufacturability. ${ }^{38,41}$

In the past few years, toughening of polymers by graphene has been explored and reported in a few publications. ${ }^{25,29-32,38,42-55}$ According to the results, it is believed that the incorporation of FG can toughen polymers including both thermoplastics and thermosets, although the understanding of the mechanism is still insufficient. In this review, the authors try to focus on the recent development on the 
toughening of polymers by graphene including their preparation, properties and mechanism. The authors also attempt to discuss the current challenges for the future development in this topic.

\section{Preparation of graphene and FG}

Graphene can be synthesized in a variety of typical methods including $(a)$ chemical vapor deposition (CVD), ${ }^{56,57}(b)$ epitaxial growth on silicon carbide, ${ }^{58,59}(c)$ exfoliation of graphite ${ }^{60,61}$ and $(d)$ chemical $^{62,63}$ or thermal ${ }^{64,65}$ reduction of graphene derivatives, such as graphene oxide (GO). The first three methods can produce small quantities of high-quality and large-size graphene sheets, which are suitable for electronic applications. By contrast, chemical or thermal reduction of GO (RGO) is the most promising method for producing graphene sheets at large scale, which is necessary for composite applications. ${ }^{6}$ Chemically reduced GO can be produced by reducing colloidal GO using chemicals such as hydrazine, ${ }^{66}$ dimethylhydrazine $^{18}$ and hydroquinone. ${ }^{67}$ On the other hand, thermal exfoliation and RGO is another approach to generate modified graphene (m-GP) sheets without the need for dispersion in a solvent. Rapid heating up to high temperature facilitates the production of RGO. However, the RGO sheets from the thermal treatment are highly wrinkled. ${ }^{65}$

GO, which is the simplest FG, can be extracted from graphite oxide in water $^{68}$ and organic solvents ${ }^{69,70}$ by sonication. The graphite oxide is typically prepared through oxidation of graphite by means of Brodie, ${ }^{71}$ Staudenmaier ${ }^{72}$ or Hummers ${ }^{73}$ methods. This is a popular route to fabricate GO sheets for their application to polymer composites. Besides GO and RGO, FG also refers to graphene derivates with other functional groups including small molecules $^{74,75}$ or polymer chains. ${ }^{76,77}$ Both covalent and noncovalent functionalization methods have been established. In this review, the authors will discuss several preparation methods that have been utilized in some studies, where polymers are reported to be successfully toughened by graphene. Wang et al ${ }^{49}$ prepared vinyl triethoxysilane-graphene (VTES-G) nanosheets by an efficient and novel method. First, GO was prepared based on Staudenmaier's method. The VTES functionalization of GO was carried out from the hydrolysis of VTES and GO. Hydrazine solution and ammonia solution were then added for reduction. Layek et al. ${ }^{50}$ synthesized sulfonated graphene (SG) from GO, which was prepared by way of Hummers' method. Three steps were shown in Figure 1 to present the SG preparation: (a) prereduction of GO using sodium borobydride; $(b)$ sulfonation with the aryl diazonium salt of sulfanilic acid and (c) postreduction with hydrazine to completely remove epoxy functionality. Fang et al. ${ }^{55}$ used solventmixing method to synthesize $\mathrm{NH}_{2}$-functionalized graphene $\left(\mathrm{NH}_{2}-\mathrm{G}\right)$ with the assistance of high-rate shear and ultrasonication. 4 , 4'-Methylene dianiline and 4, 4'-methylenebis(phenyl isocyanate) were utilized for the modification. The $\mathrm{NH}_{2}-\mathrm{G}$ was collected by centrifugation at $6000 \mathrm{rpm}$. In general, in order to enhance the compatibility and interaction between graphene and polymeric matrix, functionalization of graphene is always required for the fabrication of graphene/polymer nanocomposites. The choice of appropriate preparation method is very important, as the methods greatly affect the size, layer number and state of graphene or FG, which could influence the reinforcements for the final properties of nanocomposites.

\section{Preparation of graphene/ polymer nanocomposites}

The incorporation of graphene shows considerable enhancements in the properties of polymer that cannot normally be achieved using traditional fillers. The reported improvements are always obtained at very low loadings of graphene in the matrix..$^{25,38}$ Moreover, the improvements strongly depend on the dispersion of graphene or graphene derivates in the polymer matrix. ${ }^{29}$ Unlike CNTs, which have an issue in disentanglement of bundles during dispersion, graphene sheets are relatively flat with less entangled structure. However, they have a great tendency to agglomerate or restack in the polymer matrix to reduce configurational entropy. Therefore, it is important to prepare the nanocomposites with suitable method, which is dependent on the type and chemistry of polymer matrix. Sonication and mechanical stirring can be introduced as assistance to improve the dispersion quality of graphene.

As discussed, GO can be steadily exfoliated in water or solvents by way of hydrogen-bonding interaction. It enables a molecular level mixing between graphene and soluble polymers including polystyrene, ${ }^{18}$ poly(methyl methacrylate) ${ }^{19}$ polyurethane, ${ }^{32}$ low-density polyethylene (LDPE), ${ }^{49}$ poly(ethylene oxide) ${ }^{78}$ and poly(vinyl alcohol) (PVA). ${ }^{79} \mathrm{~A}$ good dispersion is always achieved through this method. However, solvent removal is a critical issue in some systems such as epoxy nanocomposites. Solvent mixing may not be practical for large-scale production in industry due to the cost, use of solvent and environmental issue. The most economic and scalable method for the preparation of graphene/polymer nanocomposites is melt compounding. Graphene or its derivates are mechanically mixed with polymers at elevated temperature. No solvent is required in this method. Melt compounding is a common method for preparing thermoplastic nanocomposites such as polycarbonate, ${ }^{23}$ nylon, ${ }^{47}$ poly(ethylene terephthalate) ${ }^{80}$ and polypropylene. ${ }^{81}$ In situ polymerization is another efficient way to synthesize graphene/polymer nanocomposites, especially for thermoset matrix. Graphene is firstly blent and swollen in liquid monomer. Initiator or curing agent is then diffused for polymerization with assistance of heating or radiation. This method has been widely utilized in epoxy/graphene nanocomposites development.

\section{Toughening of polymers by graphene}

Toughness is an important property that describes the ability of a material to absorb energy and plastically deform without fracturing. For brittle materials such as thermosets, fracture 




Figure 1. A schematic diagram of SG preparation from graphite powder. Reproduced from Ref. 50 with the permission from Copyright 2012 Elsevier. GO, graphene oxide; PSG, prereduced sulfonated graphene; RGO, reduced graphene oxide; SG, sulfonated graphene after reduction by hydrazine

toughness, $\mathrm{K}_{\mathrm{IC}}$ is always characterized to reveal the ability of a material containing a crack to resist fracture. To the best knowledge, there was no report on the toughness of graphene/ polymer nanocomposites before 2010 . Recently, due to the rapid development of graphene in material science, toughening of polymer by graphene has been explored and reported in some publications. Table 1 lists the enhanced polymers in toughness by the incorporation of graphene or its derivates. The preparation methods, increase in toughness and the corresponding mechanisms are summarized in the table for comparison. In their work, ${ }^{25,29-32,38,43,44,47-50,52-55}$ fracture toughness, impact strength or integration of stress-strain curves are tested to show the enhancement effect, according to the nature of the polymer nanocomposites. It can be observed that graphene toughens thermoplastics, elastomers and thermosets at low filler loadings. The toughness of most polymer nanocomposites is increased 


\begin{tabular}{|c|c|c|c|c|c|c|c|}
\hline Polymer & $\begin{array}{l}\text { Filler } \\
\text { type }\end{array}$ & $\begin{array}{c}\text { Filler } \\
\text { loading }\end{array}$ & Process for filler & $\begin{array}{l}\text { Process for } \\
\text { composite }\end{array}$ & $\begin{array}{l}\text { Increase in } \\
\text { toughness: } \%\end{array}$ & Mechanism & Ref. \\
\hline \multirow[t]{2}{*}{ PDMS } & SLG & $1 \mathrm{wt} \%$ & Thermal reduction & In situ + shear & $39^{a}$ & $\begin{array}{l}\text { Bridging + filler } \\
\quad \text { fracture }\end{array}$ & 30 \\
\hline & GNPS & $1 \mathrm{wt} \%$ & Plasma exfoliation & In situ + shear & $15^{\mathrm{a}}$ & Bridging & 30 \\
\hline \multirow[t]{2}{*}{ PU } & $\mathrm{HO}-\mathrm{G}$ & $2 w t \%$ & $\begin{array}{l}\text { Hummers + reduction } \\
\text { + sonication }\end{array}$ & $\begin{array}{l}\text { Solvent + } \\
\text { sonication }\end{array}$ & $47^{a}$ & $\begin{array}{l}\text { Sacrificial bond } \\
\text { rupture and hidden } \\
\text { length release }\end{array}$ & 31 \\
\hline & GO & $1 \mathrm{wt} \%$ & Hummers + sonication & Solvent & $50^{\mathrm{a}}$ & $\begin{array}{l}\text { Change of cross- } \\
\text { linking degree }\end{array}$ & 32 \\
\hline \multirow[t]{2}{*}{ PBI } & Graphene & $0.4 w t \%$ & $\begin{array}{c}\text { Sonication + } \\
\text { centrifugation }\end{array}$ & In situ & $100^{\mathrm{a}}$ & $\begin{array}{c}\text { Bridging + crack } \\
\text { deflection }\end{array}$ & 43 \\
\hline & GO & $0.3 w t \%$ & $\begin{array}{l}\text { Hummers + sonication } \\
+ \text { centrifugation }\end{array}$ & Solvent & $88^{a}$ & $\begin{array}{l}\text { Plastic deformation } \\
+ \text { pulling out }\end{array}$ & 44 \\
\hline Nylon-12 & $\mathrm{GO}$ & $0.6 w t \%$ & Hummers + sonication & Melt & $72^{b}$ & $\begin{array}{l}\text { Increase of } \gamma \text {-phase } \\
+ \text { decrease of crystal } \\
\text { size }\end{array}$ & 47 \\
\hline \multirow[t]{2}{*}{ Nylon-11 } & GO & $0.3 w t \%$ & Hummers + sonication & Melt & $37^{b}$ & Crack restriction & 48 \\
\hline & GO & $0.5 w t \%$ & Hummers + sonication & In situ & $52^{c}$ & $\begin{array}{l}\text { Transition of crystal } \\
\text { form }\end{array}$ & 52 \\
\hline LDPE & VTES-G & $3 w t \%$ & $\begin{array}{l}\text { Staudenmaier + } \\
\text { reduction }\end{array}$ & Solvent & $17 \cdot 7^{\mathrm{a}}$ & $\begin{array}{l}\text { Enhanced } \\
\text { interaction }\end{array}$ & 49 \\
\hline PVA & SG & $3 w t \%$ & $\begin{array}{l}\text { Hummers + reduction } \\
\text { + sulfonation }\end{array}$ & $\begin{array}{l}\text { Solvent + } \\
\text { sonication }\end{array}$ & $235^{a}$ & Dendritic structure & 50 \\
\hline \multirow[t]{6}{*}{ Epoxy } & GO & $0.1 w t \%$ & Hummers + sonication & $\begin{array}{l}\text { Solvent+ } \\
\text { in situ }\end{array}$ & $75^{b}$ & Crack restriction & 38 \\
\hline & GO & 0.54 vol\% & Brodie + sonication & $\begin{array}{l}\text { Solvent + } \\
\text { in situ }\end{array}$ & $41^{b}$ & Crack restriction & 54 \\
\hline & RGO & $0.1 w t \%$ & Thermal reduction & $\begin{array}{l}\text { Solvent + } \\
\text { in situ }\end{array}$ & $53^{b}$ & Crack restriction & 25 \\
\hline & RGO & $0.125 w t \%$ & Thermal reduction & $\begin{array}{l}\text { Solvent + } \\
\text { in situ }\end{array}$ & $65^{b}$ & Crack restriction & 53 \\
\hline & RGO & $0.2 w t \%$ & Thermal reduction & $\begin{array}{l}\text { Solvent + ball } \\
\text { mill + in situ }\end{array}$ & $52^{b}$ & $\begin{array}{l}\text { Crack bridging } \\
+ \text { debonding/ } \\
\text { delamination }\end{array}$ & 29 \\
\hline & $\mathrm{NH}_{2}-\mathrm{G}$ & $0.6 w t \%$ & $\begin{array}{c}\text { Hummers + sonication } \\
+ \text { isocyanation }\end{array}$ & $\begin{array}{l}\text { Solvent + } \\
\text { in situ }\end{array}$ & $93 \cdot 8^{a}$ & $\begin{array}{l}\text { Crack restriction + } \\
\text { flexible interphase }\end{array}$ & 55 \\
\hline
\end{tabular}

${ }^{a}$ Calculated by integrating stress-strain curves.

${ }^{b}$ Fracture toughness $\left(\mathrm{K}_{\mathrm{IC}}\right)$.

Impact strength.

GNPs, graphene nanoplatelets; GO, graphene oxide; HO-G, OH-functionalized graphene; LDPE, low-density polyethylene; $\mathrm{NH}_{2}-\mathrm{G}, \mathrm{NH}_{2}-\mathrm{functionalized}$ graphene; PBI, polybenzimidazole; PDMS, polydimethylsiloxane; PU, polyurethane; PVA, poly(vinyl alcohol); RGO, reduction of GO; SG, sulfonated graphene; SLG, single-layer graphene; VTES-G, vinyl triethoxysilane-graphene.

Table 1. Toughness of graphene/polymer nanocomposites 


\section{Offprint provided courtesy of www.icevirtuallibrary.com Author copy for personal use, not for distribution}

by up to twofold. Besides, graphene has been also reported to greatly improve the toughness of polymers in applications such as polyelectrolyte nanomembranes, ${ }^{45}$ polyvinyl acetate glue ${ }^{46}$ and polyacrylamide hydrogel. ${ }^{51}$ In this part, the authors will discuss some important issues that affect the enhancements in toughness. The possible toughening mechanisms are also analyzed.

\subsection{Effect of graphene content}

Graphene and its derivates are very efficient in toughening polymers at significant low loadings. The optimal content of graphene, however, varies in different polymer systems as shown in Table 1. The enhancement in toughness is highly dependent on the incorporated amount of graphene, as it could influence the dispersion, morphology and interactions within polymer matrix. Rafiq et al. ${ }^{47}$ investigated the effect of FG (oxygenated graphene) content on the fracture toughness of nylon-12. They found that the maximal improvement (72\%) was achieved with the addition of $0.6 \mathrm{wt} \%$ FG. According to the optical microscopy images shown in Figure 2, it can be revealed that the incorporation of FG caused an increase in the amount of $\gamma$-phase in semicrystalline nylon-12, indicating the nucleating ability of the FG. The average size of nylon crystals decreased in $0.6 \mathrm{wt} \%$ FG-incorporated nanocomposite. The decreased crystal size could benefit the toughness of nylon-12. However, with the addition of 1 and $3 \mathrm{wt} \%$ FG, the crystal size increased, which resulted in lower toughness. They also pointed out that the increasing content of FG caused



(a)

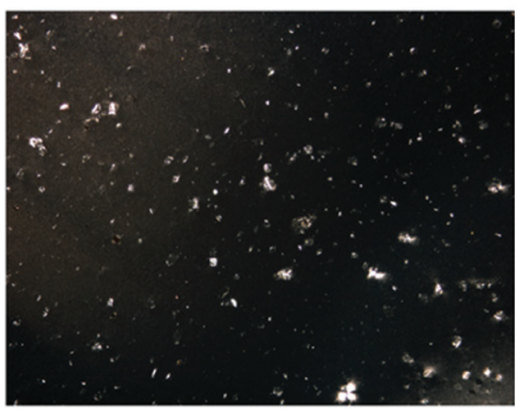

$20 \mu \mathrm{m}$

(c) deteriorated dispersion that brought about stress concentration and decreased energy dissipation ability. Therefore, excessive addition of FG reduced the fracture toughness of nylon- 12 .

In the recent study on SG toughening $\mathrm{PVA},{ }^{50}$ the $\mathrm{PVA} / \mathrm{SG}$ composites show fibrillar, dentritic and rod-like structures (Figure 3) for SG1, SG3 and SG5 samples, respectively. The number represents weight per cent of SG. Obviously, the variations of SG content changed the morphology of nanofillers in the PVA matrix, and finally determined the enhancement in toughness. As shown in Figure 3, both SG1 and SG3 formed interlamellar and interfibrillar structure with PVA lamella. It resulted in a significant increase in the toughness by over $200 \%$. By contrast, the SG sheets aggregated when the content of SG was $5 \mathrm{wt} \%$. They could not enter into the interlamellar amorphous layer of PVA, making the value in the crystal and amorphous overlayer thickness unchanged, corresponding to unchanged toughness as pure PVA. The maximal enhancement in toughness was observed in SG3/PVA composite. For graphene toughening polymer, the incorporation of appropriate content of graphene could form a good dispersion and interactive network structure in the matrix. It could contribute to the increase in toughness. However, at higher graphene fraction, it is generally recognized that graphene sheets could agglomerate with poor dispersion quality, which is responsible for the decrease/disappearance of the toughness enhancements. ${ }^{38,53}$

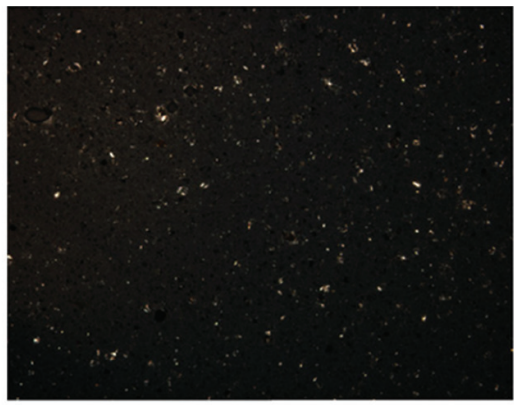

(b)

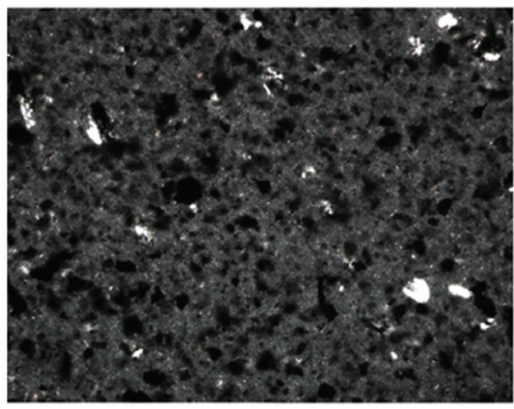

(d)

Figure 2. Polarized optical microscopic images (a-d) of the nylon 12 and its composites with 0.6, 1 and 3 wt\% FG, respectively. FG, functionalized graphene. Reproduced from Ref. 47 




(a)

(b)

PVA:SG = 95:5

Cohesive force

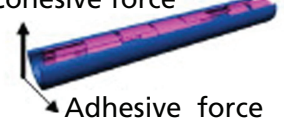

(c)

Aggregation induced bended SG sheets coated with PVA

Figure 3. Supramolecular organization of PVA and SG for (a) SG1

(b) SG3 and (c) SG5 samples producing different morphologies.

PVA, poly(vinyl alcohol); SG, sulfonated graphene. Reproduced from

Ref. 50 with the permission from Copyright 2012 Elsevier

\subsection{Effect of graphene thickness (layer number) and size}

Graphene is a single-atom thick sheet of hexagonally arranged, $\mathrm{sp}^{2}$-bonded carbon atoms. The thickness of the monolayer graphene is $0.34 \mathrm{~nm}$. In practice, it is very difficult to achieve single-layer graphene (SLG) in the polymer matrix. Few-layer or multilayer graphene sheets are commonly used in composite science. The term 'graphene' used by researchers and manufacturers could refer to graphene that contains from several, even up, to hundreds of layers, which seems unscientific or contradictory. Layer number is a key variable in graphene science and technology, and should be specified accurately wherever possible. According to the recent recommended nomenclature for 2D carbon materials, 82 'graphene' is specified with regard to the layer number. The terms include graphene layer (one layer), bilayer graphene (two layers), trilayer graphene (three layers), few-layer graphene (two to five layers), multilayer graphene (two to ten layers) and graphite nanoplates (thickness $<100 \mathrm{~nm}$ ). This nomenclature could better help us to understand the effect of graphene thickness on the properties of composites.

$\mathrm{Xu}$ et al. $^{30}$ investigated graphene/polydimethylsiloxane (PDMS) nanocomposites by incorporation of SLG and graphene nanoplatelets (GNPs; three to five layers), respectively. They found SLG showed a better improvement in the toughness of the polymer than GNPs at the same filler loading. From the SEM images of the fracture surface, it can be observed that the polymer was pulled out of the SLG filler before cracking of the filler. The failure mechanisms of SLG in PDMS seemed quite different from those of GNPs as indicated in Table 1. This result demonstrates the importance of the layer number in the toughness enhancement. Graphene with fewer layers could better benefit the toughness.

Recently, the authors fabricated a series of epoxy/GO nanocomposites by adding three different sizes of GO sheets, namely, GO-1, GO-2 and GO-3. ${ }^{38}$ Their thickness is about $1 \mathrm{~nm}$ 


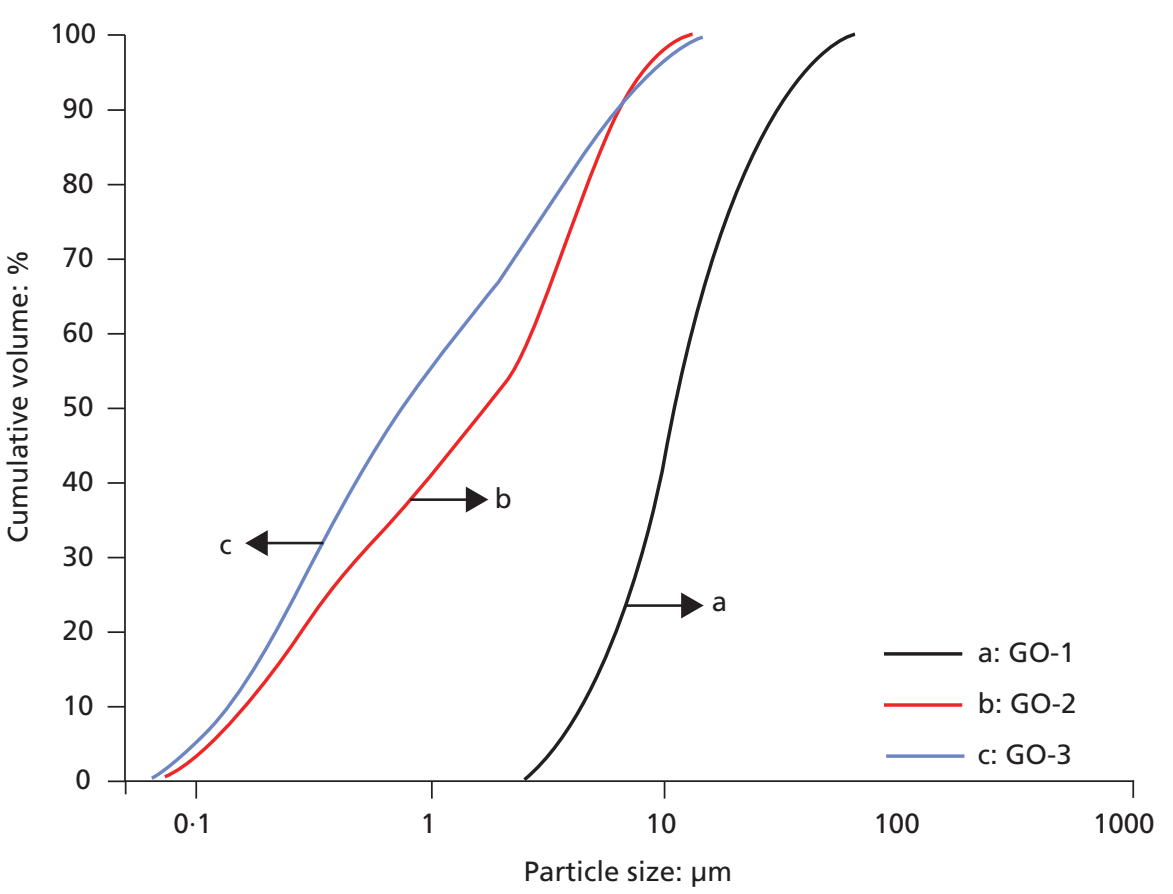

Figure 4. Cumulative volume plotted against particle size of (a) GO-1,

(b) GO-2 and (c) GO-3. GO, graphene oxide. Reproduced from Ref. 38

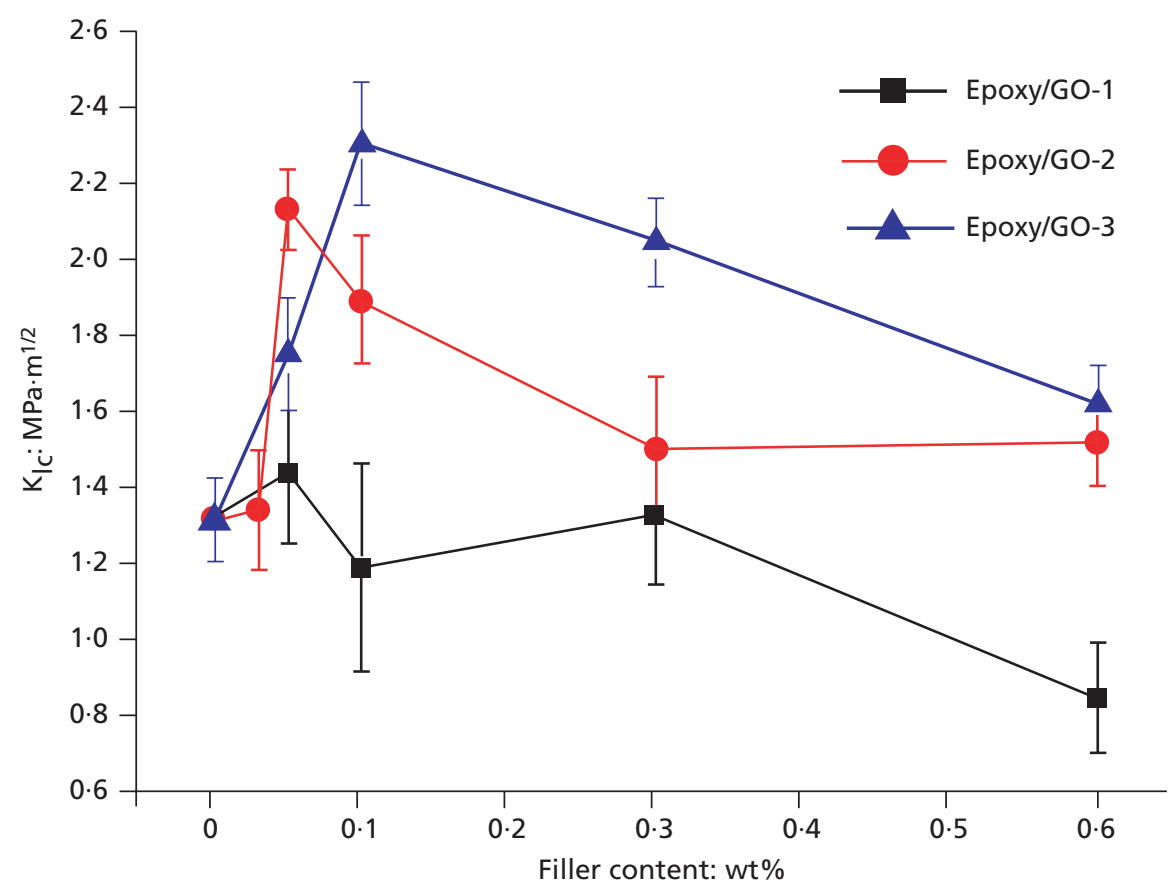

Figure 5. $K_{\mathrm{lC}}$ plotted against GO content for the epoxy

nanocomposites. $K_{\mathrm{I}}$, fracture toughness; $\mathrm{GO}$, graphene oxide.

Reproduced from Ref. 38 


\section{Offprint provided courtesy of www.icevirtuallibrary.com Author copy for personal use, not for distribution}

(two to five layers). The size distributions of the GO sheets are shown in Figure 4. The average size for GO-1, GO-2 and GO-3 are $10.79,1.72$ and $0.70 \mu \mathrm{m}$, respectively. The different sized GOs show dramatically different effects on the fracture toughness of epoxy (Figure 5). The GO-3 with smaller sheet size $(0 \cdot 70 \mu \mathrm{m})$ brought about a lower stress concentration in the matrix, thus gave rise to better toughness reinforcement. However, Chatterjee et al. ${ }^{83}$ believed large-size graphene nanoplatelets (thickness of 6-15 nm) could performed better. In a matter of fact, the GNPs they used were graphite nanoplates rather than few-layer graphene sheets. Hence, their result may be not applicable for graphene toughening polymer.

\subsection{Effect of graphene states}

As a nanosize material, graphene sheets are thermodynamically unstable in polymer matrix. The graphene sheets have a great tendency to agglomerate to reduce configurational entropy, particularly when the phase transition occurs during processing. ${ }^{38}$ The actual thickness of the agglomerated graphene sheets in the matrix is always increased. The dispersion quality greatly depends on the preparation conditions such as temperature, mixing rate and viscosity, which could affect the state of graphene in composites. Tang et al. ${ }^{29}$ studied the effect of graphene (RGO) dispersion on the fracture toughness of epoxy resins. Different dispersions of RGO sheets in epoxy resin were prepared with and without ball mill mixing. It was found that the highly dispersed RGO resulted in a higher toughness improvement (52\%), compared with $24 \%$ increase measured in the poorly dispersed RGO composite. On the basis of the observations on the fracture surface, the highly dispersed RGO showed much more tortuous and fine river-like structure that was able to consume energy when facture occurred.

Moreover, the graphene surface exhibits wrinkle like ${ }^{19,53,85}$ rather than flattened texture as shown in Figure $6 .{ }^{84}$ The degree (wavelength and amplitude) of the wrinkles is related to the

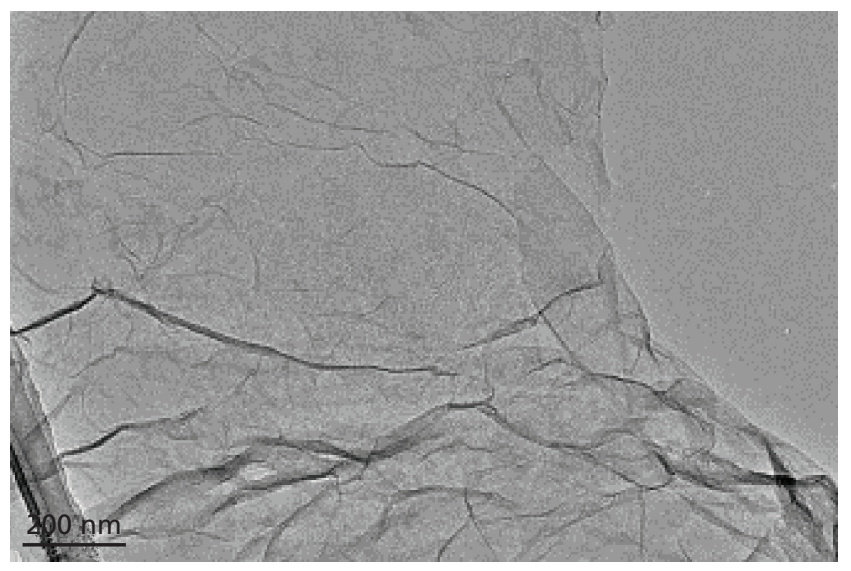

Figure 6. TEM image of graphene. TEM, transmission electron microscropy. Reproduced from Ref. 84 with the permission from Copyright 2012 Elsevier graphene size, preparation method and interfacial adhesion with the polymer chains. For instance, graphene with bigger size possesses large-size wrinkles. ${ }^{86}$ The graphene sheets prepared from thermal reduction are highly wrinkled. Also, the wrinkles are the main source that could pose bending, folding and twisting of graphene sheets.$^{87}$ Thus, the surface roughness is significantly increased. The regularity and geometric continuity are reduced accordingly. The wrinkled surface texture of graphene could affect the mechanical properties of the composites. Rafiee et al..$^{53}$ suggested that the wrinkles improved mechanical interlocking and adhesion with the polymer matrix, which may be positive for graphene enhancement. However, the high wrinkled structure of graphene led to its low effective aspect ratio and resulted in changes of the effective performance in the polymer matrix. ${ }^{48}$ Shen et al. ${ }^{88}$ found that the wrinkles reduced the Young's modulus of GO papers by $60 \%$ of the pristine value. It was very important to minimize the adverse effect of wrinkles to improve the stress transfer between graphene sheets and polymer matrix. According to our investigations, ${ }^{38}$ the presence of the wrinkles was believed to reduce the load-transfer efficiency in graphene sheets, and brought about serious local stress concentrations in the regions surrounding the fillers, corresponding to reduced toughness of the composites.

\subsection{Effect of interfacial bonding}

It has been wildly reported that the incorporation of graphene improves modulus, stiffness, hardness and thermal stability of polymers. ${ }^{3,6}$ These benefits mainly result from the enhanced interfacial adhesion that enables the transfer of the mechanical properties of graphene. The improvements are greatly dependent on the load-transfer efficiency. Therefore, it is necessary to investigate the effect of interfacial bonding on the toughness of polymers. Functionalization of graphene is a common step to achieve good interfacial bonding. Wang et al. ${ }^{49}$ fabricated FG nanosheets with VTES. The VTES-G chemically interacted with LDPE molecules. Due to the strong interfacial bonding, the LDPE/ VTES-G composites showed enhanced toughness than neat LDPE. On the contrary, incorporation of graphene (non-functionalized) worsened the toughness of LDPE. The interfacial bonding seems critical in the toughness enhancement of LDPE. Zaman et al. ${ }^{89}$ found that the addition of m-GP significantly increased the fracture toughness of epoxy at high filler loadings, owing to high interface strength. At low filler fractions, the unmodified graphene, however, provided better enhancements in toughness than m-GP. Moreover, unmodified graphene has been also reported could toughen other polymer systems. ${ }^{30,43}$ Therefore, the influence of the interfacial bonding on the toughness of composites may depend on the type of polymer and the corresponding mechanism. A strong interfacial adhesion could be essential in thermoplastic nanocomposites. For thermosets such as epoxy resins, the enhanced bonding between molecules and functional groups on graphene always increases the cross-link density in the area close to the fillers, and confines the interfacial chains by restricting their motions. The glass transition 


\section{Offprint provided courtesy of www.icevirtuallibrary.com Author copy for personal use, not for distribution}

temperature $\left(T_{\mathrm{g}}\right)$ of the composites is increased. Theoretically, it would be negative for toughness. Nevertheless, significant improvements in toughness have been reported in FG/epoxy system. Fang et al..$^{55}$ constructed flexible interphase structure between epoxy and graphene, where the cross-link density was lower than the bulk. The $T_{\mathrm{g}}$ was decreased compared with pure epoxy. The increase in toughness is in fact comparable to the FG/epoxy systems with rigid interfacial bonding as shown in Table 1 . The interfacial bonding may not be the key factor in graphene toughening thermosets, as the mechanism indicates the importance of the 2D nature of graphene that effectively resists the crack propagation. More experiments need to be carried out to reveal the effect of interphase on toughness of polymers in the future.

\subsection{Graphene toughening epoxy}

Epoxy resins are the most important thermosets in industry for various applications. ${ }^{90}$ They possess excellent mechanical properties due to high cross-linked structure. However, it always results in poor fracture toughness that limits their utilizations in high-performance areas. Compared with other polymeric systems, epoxy resins have been well studied recently in terms of toughness enhancement and mechanism, although they are still matters of debate. Epoxy resins have been reported to be successfully toughened by nanofillers such as metallic oxide (aluminum oxide and titanium oxide), ${ }^{91}$ nanosilica, ${ }^{92}$ clay, ${ }^{93} \mathrm{CB},{ }^{94} \mathrm{CNTs}^{95}$ and graphene. $.8,53,55$ The optimal loadings of the nanofillers for toughness improvement are summarized in Table 2. It can be observed that graphene toughens epoxy resins at very low loading. To achieve comparable increase

\begin{tabular}{lccc}
$\begin{array}{l}\text { Nanofiller } \\
\text { in epoxy } \\
\text { matrix }\end{array}$ & $\begin{array}{c}\text { Filler loading: } \\
\text { wt } \%\end{array}$ & $\begin{array}{c}\text { Increase in fracture } \\
\text { toughness: } \%\end{array}$ & Ref. \\
$\begin{array}{l}\text { Aluminum } \\
\text { oxide }\end{array}$ & 5 & 65 & 91 \\
$\begin{array}{l}\text { Titanium } \\
\text { oxide }\end{array}$ & 10 & 65 & 91 \\
Nanosilica & 14.8 & 62 & 92 \\
Nanoclay & 2.5 & 78 & 93 \\
CB & 3 & 23 & 94 \\
CNTs & 0.5 & 43 & 95 \\
GO & 0.1 & 75 & 38 \\
RGO & 0.125 & 65 & 53 \\
NH ${ }_{2}-G$ & 0.6 & 93.8 & 55 \\
\hline
\end{tabular}

$\mathrm{CB}$, carbon black; CNTs, carbon nanotubes; GO, graphene oxide; $\mathrm{NH}_{2}-\mathrm{G}, \mathrm{NH}_{2}$-functionalized graphene; $\mathrm{RGO}$, reduction of $\mathrm{GO}$.

Table 2. Comparison of reinforcement efficiency in nanofiller toughening epoxy in toughness, the required weight fraction of other nanofillers in epoxy ranges from several folds to 100 -fold larger than graphene. As a 2D nanofiller with high aspect ratio, graphene based materials are superior to other fillers according to Faber and Evans crack deflection modeling. ${ }^{96}$ This theory indicates that the tilting of crack front acts as a very important toughening rule for circular plate shaped particles. On the contrary, neither the sphere-shaped nor the rod-shaped particles derive noticeable toughening from the crack tilting process. According to the reported experimental and theoretical work, graphene could be the most efficient nanofillers in toughening epoxy resins.

The fact that graphene toughens epoxy resins by restriction of the crack propagation is regarded as main toughening mechanism. The evidence has been provided by researchers based on plenty of fractography analysis of the composites. Figure 7 shows the optical microscopic images of the fracture surface for the pure resin and its nanocomposites with increasing amount of GO. ${ }^{38}$ It can be seen that the cracks grow in the direction of crack propagation for the pure epoxy. By addition of GO sheets, the development of cracks is effectively disturbed. In particular, the number of the cracks increases, but the average size of the cracks reduces as the GO content increases. Meanwhile, massive subcracks are induced in the fracture surface of the nanocomposites. This sufficiently demonstrates the role of graphene in toughening epoxy. The crack propagation is deflected, tilted or suppressed due to the presence of 2D structured graphene sheets. The breakdown of propagating cracks certainly reduce local applied stress, thus contributes to the resistance of fracture. Accordingly, this is one of the main reasons for the improvement of the fracture toughness. Other mechanisms such as crack bridging, debonding and delamination have been also reported..$^{29}$

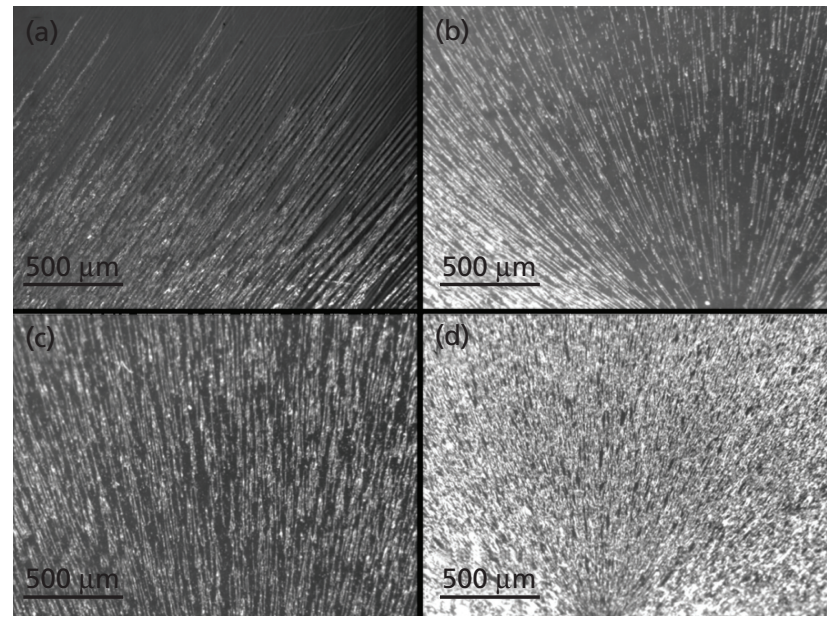

Figure 7. Optical microscopic images of crack propagation on the fracture surfaces (whitening zone) for (a) the pure epoxy and its nanocomposites with (b) $0.05 \mathrm{wt} \% \mathrm{GO}$, (c) $0.1 \mathrm{wt} \% \mathrm{GO}$ and (d) 0.3 wt $\%$ GO. GO, graphene oxide. Reprodcued from Ref. 38 


\section{Conclusion and remarks}

Graphene and its derivates are very promising carbon nanofillers that can improve the electrical, thermal and mechanical properties of polymers at extremely low loadings. Compared with other conventional nanofillers, such as clay, $\mathrm{CB}$ and CNTs, graphene may be preferred due to its high aspect ratio, surface area, electrical conductivity, thermal stability and thermal conductivity. Its advantages over other fillers have been reported. However, their potential in reinforcing polymers is not fully revealed. Graphene toughening polymers is one of the most important issues in its applications in composite science. Graphene can be synthesized by CVD, epitaxial growth, exfoliation of graphite and chemical or thermal reduction methods. The first three methods can produce high-quality graphene but limited quantity, while the reduction method is suitable for large-scale production of reinforcements for polymer composites. Functionalization of graphene is regarded as an efficient step to improve the dispersion in polymeric matrices and achieve enhanced interfacial adhesion. Solvent mixing, melt compounding and in situ polymerization are the common methods for the preparation of graphene/polymer nanocomposites. Incorporation of graphene shows significant improvement in the polymer toughness, according to the reported work. Graphene content, layer number, size, state and its interfacial bonding with matrix greatly affect the toughness reinforcement.

The loading fraction of graphene influences the enhancement of toughness, as it relates to the morphology and dispersion of graphene in polymers. The optimal content of graphene, however, varies in different polymer systems. Excessive incorporation of graphene always causes agglomeration with reduced dispersion quality that is negative for toughness. By the addition of $0.6 \mathrm{w} \% \mathrm{GO}$, the amount of $\gamma$-phase of nylon- 12 increased with decreased crystal size, which directly contributed to the toughness improvement. The morphology of graphene in PVA varied dramatically at different filler loadings. Incorporation of $1 \mathrm{wt} \% \mathrm{SG}$ showed dentritic structure that resulted in the best enhancement. Furthermore, SLG was proved better than few-layer graphene sheets in toughening PDMS. The failure mechanisms in the two composite systems were quite different. The size effect was also revealed based on graphene/epoxy composites. Graphene with smaller sheet size gave a better reinforcement effect on toughness. These results are useful to guild the further development of graphene toughening polymers. However, more experiments should be carried out based on a wide range of polymeric systems, in order to fully understand the effects of the content, thickness and size of graphene on the property. Besides, analytical modeling could be an effective approach to reveal the correlations between these graphene parameters and toughness. Such models have been discussed by Zhao and Hoa. ${ }^{97}$ Since these parameters are controllable in processing, it makes the modeling results valuable to guild experimental strategies.

The enhancement in toughness also relates to the states of graphene in the polymeric matrix. Unlike the parameters discussed above, the states of graphene such as orientation, dispersion and wrinkling degree in composite are difficult to control. Thus, the modeling on these aspects may be less effective when applies to practical fabrication and characterization of composites. It has been reported that highly dispersed graphene resulted in a higher toughness improvement than that of poorly dispersed graphene composite. Sonication and mechanical mixing (ball mill) can be utilized to improve the dispersion quality. More smart fabricating techniques will be also required. The wrinkle-like surface of graphene could affect the mechanical properties of composites. However, the understanding of the effect of wrinkles is still in debate. Some reports suggested that the wrinkles improved mechanical interlocking and adhesion with the polymer matrix, which was positive for reinforcement. On the contrary, the winkles were found could significantly reduce the modulus of the pristine value of graphene. The authors believe that the wrinkled structure leads to low effective aspect ratio. It could reduce load-transfer efficiency and bring about serious stress concentrations, corresponding to reduced toughness. Therefore, flatten the wrinkles and fully utilize the inherently properties of graphene is important. A proper preparation method of graphene is critical in controlling the degree of wrinkles. A few practical methods have been suggested to flatten wrinkles such as improving inter-sheet interaction by chemical cross-linking of GO sheets. ${ }^{98,99}$

Adhesion is another important factor in designing composite materials. Strong interfacial bonding is always required to realize the superior mechanics of nanofillers to the polymer matrix. In graphene toughening polymers, the effect of the interfacial bonding on toughness is ambiguous with very limited experimental evidence. The influences could depend on the type of polymer and its mechanism. A strong interfacial adhesion could be essential in thermoplastic nanocomposites. For thermosets, the interfacial bonding may not be the key factor in toughness enhancement according to the crack restriction mechanism. More comparative studies and modeling work are necessary to investigate this effect.

Graphene toughening epoxy resins has been well studied, compared with other polymeric systems. The main mechanism was established that crack propagation is deflected, tilted or suppressed due to the presence of 2D graphene sheets. Graphene is the most efficient nanofillers in toughening epoxy. However, the understanding of toughening mechanisms responsible for other graphene/polymer composites is insufficient, which also needs further explorations.

\section{REFERENCES}

1. Balazs, A. C.; Emrick, T.; Russell, T. P. Nanoparticle polymer composites: where two small worlds meet. Science 2006, 314 , $1107-1110$

2. Winey, K. I.; Vaia, R. A. Polymer nanocomposites. $M R S$ Bulletin 2007, 32(4), 314-322. 
3. Kuilla, T.; Bhadra, S.; Yao, D.; Kim, N. H.; Bose, S.; Lee, J. $\mathrm{H}$. Recent advances in graphene based polymer composites. Progress in Polymer Science 2010, 35, 1350-1375.

4. Huang, J. C. Carbon black filled conducting polymers and polymer blends. Advances in Polymer Technology 2002, 21(4), 299-313.

5. Moniruzzaman, M.; Winey, K. I. Polymer nanocomposites containing carbon nanotubes. Macromolecules 2006, 39(16), 5194-5205.

6. Kim, H.; Abdala, A. A.; Macosko, C. W. Graphene/polymer nanocomposites. Macromolecules 2010, 43, 6515-6530.

7. Gao, F. Clay/polymer composites: the story. Materials Today 2004, 7(11), 50-55.

8. Koo, J. H. Polymer Nanocomposites. New York: McGraw-Hill, 2006.

9. Debdatta, R. Handbook of Thermoset Resins. Shawbury: iSmithers, 2009.

10. Meyer, J. C.; Geim, A. K.; Katsnelson, M. I.; Novoselov, K. S.; Booth, T. J.; Roth, S. The structure of suspended graphene sheets. Nature 2007, 446, 60-63.

11. Geim, A. K. Graphene: status and prospects. Science 2009, 324, 1530-1534.

12. Allen, M. J.; Tung, V. C.; Kaner, R. B. Honeycomb carbon: a review of graphene. Chemical Reviews 2010, 110, 132-145.

13. Lee, C.; Wei, X.; Kysar, J. W.; Hone, J. Measurement of the elastic properties and intrinsic strength of monolayer graphene. Science 2008, 321, 385-388.

14. Stoller, M. D.; Park, S.; Zhu, Y.; An, J.; Ruoff, R. S. Graphenebased ultracapacitors. Nano Letters 2008, 8(10), 3498-3502.

15. Balandin, A. A.; Ghosh, S.; Bao, W.; Calizo, I.; Teweldebrahn, D.; Miao, F.; Lau, C. N. Superior thermal conductivity of single-layer graphene. Nano Letters 2008, 8(3), 902-907.

16. Du, X.; Skachko, I.; Barker, A.; Andrei, E. Y. Approaching ballistic transport in suspended graphene. Nature Nanotechnology 2008, 3, 491-495.

17. Novoselov, K. S.; Geim, A. K.; Morozov, S. V.; Jiang, D.; Zhang, Y.; Dubonos, S. V.; Grigorieva, I. V.; Firsov, A. A. Electric field effect in atomically thin carbon films. Science 2004, 306, 666-669.

18. Stankovich, S.; Dikin, D. A.; Dommett, G. H. B.; Kohlhaas, K. M.; Zimney, E. J.; Stach, E. A.; Piner, R. D.; Nguyen, S. T.; Ruoff, R. S. Graphene-based composite materials. Nature 2006, 442, 282-286.

19. Ramanathan, T.; Abdala, A. A.; Stankovich, S.; Dikin, D. A.; Herrera-Alonso, M.; Piner, R. D.; Adamson, D. H.; Schniepp, H. C.; Chen, X.; Ruoff, R. S.; Nguyen, S. T.; Aksay, I. A.; Prud'Homme, R. K.; Brinson, L. C. Functionalized graphene sheets for polymer nanocomposites. Nature Nanotechnology 2008, 3(6), 327-331.

20. Xu, Y.; Wang, Y.; Liang, J.; Huang, Y.; Ma, Y.; Wan, $\mathrm{X}$.; Chen, Y. A hybrid material of graphene and poly (3,4-ethyldioxythiophene) with high conductivity, flexibility, and transparency. Nano Research 2009, 2, 343-348.
21. Quan, H.; Zhang, B.; Zhao, Q.; Yuen, R. K. K.; Li, R. K. Y. Facile preparation and thermal degradation studies of graphite nanoplatelets (GNPs) filled thermoplastic polyurethane (TPU) nanocomposites. Composites Part A: Applied Science and Manufacturing 2009, 40, 1506-1513.

22. Eda, G.; Chhowalla, M. Graphene-based composite thin films for electronics. Nano Letters 2009, 9, 814-818.

23. Kim, H.; Macosko, C. W. Processing-property relationships of polycarbonate/graphene nanocomposites. Polymer 2009, 50, 3797-3809.

24. Cai, D.; Song, M. Recent advance in functionalized graphene/ polymer nanocomposites. Journal of Materials Chemistry 2010, 20, 7906-7915.

25. Rafiee, M. A.; Rafiee, J.; Wang, Z.; Song, H.; Yu, Z.; Koratkar, N. Enhanced mechanical properties of nanocomposites at low graphene content. ACS Nano 2009, 3, 3884-3890.

26. Steurer, P.; Wissert, R.; Thomann, R.; Muelhaupt, R. Functionalized graphenes and thermoplastic nanocomposites based upon expanded graphite oxide. Macromolecular Rapid Communications 2009, 30, 316-327.

27. Yavari, F.; Rafiee, M. A.; Rafiee, J.; Yu, Z-Z.; Koratkar, N. Dramatic increase in fatigue life in hierarchical graphene composites. ACS Applied Materials and Interfaces 2010 , 2(10), 2738-2743.

28. Zaman, I.; Kuan, H. C.; Dai, J.; Kawashima, N.; Michelmore, A.; Sovi, A.; Dong, S.; Luong, L.; Ma, J. From carbon nanotubes and silicate layers to graphene platelets for polymer nanocomposites. Nanoscale 2012, 4, 4578-4586.

29. Tang, L. C.; Wan, Y. J.; Yan, D.; Pei, Y. B.; Zhao, L.; Li, Y. B.; Wu, L. B.; Jiang, J. X.; Lai, G. Q. The effect of graphene dispersion on the mechanical properties of graphene/epoxy composites. Carbon 2013, 60, 16-27.

30. Xu, P.; Loomis, J.; Bradshaw, R. D.; Panchapakesan, B. Load transfer and mechanical properties of chemically reduced graphene reinforcements in polymer composites. Nanotechnology 2012, 23, 505713.

31. Chen, Z.; Lu, H. Constructing sacrificial bonds and hidden lengths for ductile graphene/polyurethane elastomers with improved strength and toughness. Journal of Materials Chemistry 2012, 22, 12479-12490.

32. Cai, D.; Jin, J.; Yosoh, K.; Rafiq, R.; Song, M. High performance polyurethane/functionalized graphene nanocomposites with improved mechanical and thermal properties. Composites Science and Technology 2012, 72, 702-707.

33. Potts, J. R.; Dreyer, D. R.; Bielawski, C. W.; Ruoff, R. S. Graphene-based polymer nanocomposites. Polymer 2011, 52, $5-25$.

34. Singh, V.; Joung, D.; Zhai, L.; Das, S.; Khondaker, S. I.; Seal, S. Graphene based materials: past, present and future. Progress in Materials Science 2011, 56, $1178-1271$. 
35. Wang, X.; Jin, J.; Song, M. Cyanate ester resin/graphene nanocomposite: curing dynamics and network formation. European Polymer Journal 2012, 48, 1034-1041.

36. Lu, H.; Chen, Z.; Ma, C. Bioinspired approaches for optimizing the strength and toughness of graphene-based polymer nanocomposites. Journal of Materials Chemistry 2012, 22, 16182-16190.

37. Fang, M.; Wang, K. G.; Lu, H. B.; Yang, Y. L.; Nutt, S. Covalent polymer functionalization of graphene nanosheets and mechanical properties of composites. Journal of Materials Chemistry 2009, 19, 7098-7105.

38. Wang, X.; Jin, J.; Song, M. An investigation of the mechanism of graphene toughening epoxy. Carbon 2013, 65, 324-333.

39. Sengupta, R.; Bhattacharya, M.; Bandyopadhyay, S.; Bhowmick, A. K. A review on the mechanical and electrical properties of graphite and modified graphite reinforced polymer composites. Progress in Polymer Science 2011, 36(5), 638-670.

40. Launey, M. E.; Ritchie, R. O. On the fracture toughness of advanced materials. Advanced Materials 2009, 21(20), 2103-2110.

41. Wu, S. J.; Mi, F. L. Cure kinetics of a cyanate ester blended with poly (phenylene oxide). Polymer International 2006, 55, 1296-1303.

42. Liu, L.; Gao, Y.; Liu, Q.; Kuang, J.; Zhou, D.; Ju, S.; Han, B.; Zhang, Z. High mechanical performance of layered graphene oxide/poly(vinyl alcohol) nanocomposite films. Small 2013, 9(14), 2466-2472.

43. Wang, Y.; Shi, Z.; Fang, J.; Xu, H.; Ma, X.; Yin, J. Direct exfoliation of graphene in methanesulfonic acid and facile synthesis of graphene/polybenzimidazole nanocomposites. Journal of Materials Chemistry 2011, 21, 505-512.

44. Wang, Y.; Shi, Z.; Fang, J.; Xu, H.; Yin, J. Graphene oxide/ polybenzimidazole composites fabricated by a solventexchange method. Carbon 2011, 49, 1199-1207.

45. Kulkarni, D. D.; Choi, I.; Singamaneni, S. S.; Tsukruk, V. V. Graphene oxide polyelectrolyte nanomembranes. ACS Nano 2010, 4(8), 4667-4676.

46. Khan, U.; May, P.; Porwal, H.; Nawaz, K.; Coleman, J. N. Improved adhesive strength and toughness of polyvinyl acetate glue on addition of small quantities of graphene. ACS Applied Materials and Interfaces 2013, 5, 1423-142.

47. Rafiq, R.; Cai, D.; Jin, J.; Song, M. Increasing the toughness of nylon 12 by the incorporation of functionalized graphene. Carbon 2010, 48, 4309-4314.

48. Jin, J.; Rafiq, R.; Gill, Y. Q.; Song, M. Preparation and characterization of high performance of graphene/nylon nanocomposites. European Polymer Journal 2013, 49, 2617-2626.

49. Wang, J.; Xu, C.; Hu, H.; Wan, L.; Chen, R.; Zheng, H.; Liu, F.; Zhang, M.; Shang, X.; Wang, X. Synthesis, mechanical, and barrier properties of LDPE/graphene nanocomposites using vinyl triethoxysilane as a coupling agent. Journal of Nanoparticle Research 2011, 13, 869-878.

50. Layek, R. K.; Samanta, S.; Nandi, A. K. The physical properties of sulfonated graphene/poly(vinyl alcohol) composites. Carbon 2012, 50, 815-827.

51. Liu, R.; Liang, S.; Tang, X-Z.; Yan, D.; Li, X.; Yu, Z-Z. Tough and highly stretchable graphene oxide/polyacrylamide nanocomposite hydrogels. Journal of Materials Chemistry 2012, 22, 14160-14167.

52. Yuan, D.; Wang, B.; Wang, L.; Wang, Y.; Zhou, Z. Unusual toughening effect of graphene oxide on the graphene oxide/nylon 11 composites prepared by in situ melt polycondensation. Composites: Part B 2013, 55, 215-220.

53. Rafiee, M. A.; Rafiee, J.; Srivastava, I.; Wang, Z.; Song, H.; Yu, Z-Z.; Koratkar, N. Fracture and fatigue in graphene nanocomposites. Small 2010, 6(2), 179-183.

54. Qiu, J.; Wang, S. Enhancing polymer performance through graphene sheets. Journal of Applied Polymer Science 2011, 119, 3670-3674.

55. Fang, M.; Zhang, Z.; Li, J.; Zhang, H.; Lu, H.; Yang, Y. Constructing hierarchically structured interphases for strong and tough epoxy nanocomposites by amine-rich graphene surfaces. Journal of Materials Chemistry 2010, 20, 9635-9643.

56. Dervishi, E.; Li, Z.; Watanabe, F.; Biswas, A.; Xu, Y.; Biris, A. R.; Saini, V.; Biris, A. S. Large-scale graphene production by RF-cCVD method. Chemical Communications 2009, 27, 4061-4063.

57. Li, X.; Cai, W.; An, J.; Kim, S.; Nah, J.; Yang, D.; Piner, R.; Velamakanni, A.; Jung, I.; Tutuc, E.; Banerjee, S. K.; Colombo, L.; Ruoff, R. S. Large-area synthesis of high-quality and uniform graphene films on copper foils. Science $\mathbf{2 0 0 9}$, 324, 1312-1314.

58. de Heer, W. A.; Berger, C.; Wu, X.; First, P. N.; Conrad, E. H.; Li, X.; Li, T.; Sprinkle, M.; Hass, J.; Sadowski, M. L.; Potemski, M.; Martinez, G. Epitaxial graphene. Solid State Communications 2007, 143, 92-100.

59. Alexander, M.; Oleg, P. Density functional study of graphene overlayers on SiC. Physica Status Solidi B 2008, 245(7), 1425-1435.

60. Zhao, W.; Fang, M.; Wu, F.; Wu, H.; Wang, L.; Chen, G. Preparation of graphene by exfoliation of graphite using wet ball milling. Journal of Materials Chemistry 2010, 20, 5817-5819.

61. Lin, Y.; Jin, J.; Kusmartsevab, O.; Song, M. Preparation of pristine graphene sheets and large-area/ultrathin graphene films for high conducting and transparent applications. The Journal of Physical Chemistry C 2013, 117, 17237-17244.

62. Park, S.; An, J.; Piner, R. D.; Jung, I.; Yang, D.; Velamakanni, A.; Nguyen, S. T.; Ruoff, R. S. Aqueous suspension and characterization of chemically modified graphene sheets. Chemistry of Materials 2008, 20, 6592-6594. 
63. Pei, S.; Cheng, H-M. The reduction of graphene oxide. Carbon 2012, 50, 3210-3228.

64. Schniepp, H. C.; Li, J-L.; McAllister, M. J.; Sai, H.; HerreraAlonso, M.; Adamson, D. H.; Prud'homme, R. K.; Car, R.; Saville, D. A.; Aksay, I. A. Functionalized single graphene sheets derived from splitting graphite oxide. The Journal of Physical Chemistry B 2006, 110, 8535-8539.

65. McAllister, M. J.; Li, J-L.; Adamson, D. H.; Schniepp, H. C.; Abdala, A. A.; Liu, J.; Herrera-Alonso, M.; Milius, D. L.; Car, R.; Prud'homme, R. K.; Aksay, I. A. Single sheet functionalized graphene by oxidation and thermal expansion of graphite. Chemistry of Materials 2007, 19(18), 4396-4404.

66. Stankovich, S.; Dikin, D. A.; Piner, R. D.; Kohlhaas, K. A.; Kleinhammes, A.; Jia, Y.; Wu, Y.; Nguyen, S. T.; Ruoff, R. $S$. Synthesis of graphene-based nanosheets via chemical reduction of exfoliated graphite oxide. Carbon 2007, 45(7), 1558-1565.

67. Wang, G.; Yang, J.; Park, J.; Gou, X.; Wang, B.; Liu, H.; Yao, J. Facile synthesis and characterization of graphene nanosheets. The Journal of Physical Chemistry C 2008, 112, 8192-8195.

68. Dikin, D. A.; Stankovich, S.; Zimney, E. J.; Piner, R. D.; Dommett, G. H. B.; Evmenenko, G.; Nguyen, S. T.; Ruoff, R. $S$. Preparation and characterization of graphene oxide paper. Nature 2007, 448, 457-460.

69. Cai, D.; Song, M. Preparation of fully exfoliated graphite oxide nanoplatelets in organic solvents. Journal of Materials Chemistry 2007, 17, 3678-3680.

70. Dreyer, D. R.; Park, S.; Bielawski, C. W.; Ruoff, R. S. The chemistry of graphene oxide. Chemical Society Reviews 2009, 39, 228-240.

71. Brodie, B. C. On the atomic weight of graphite. Philosophical Transactions of the Royal Society of London 1859, 149, 249-259.

72. Staudenmaier, L. Verfahren zur Darstellung der Graphitsäure. Berichte der deutschen chemischen Gesellschaft 1898, 31, 1481-1487.

73. Hummers, W. S.; Offeman, R. E. Preparation of graphitic oxide. Journal of the American Chemical Society 1958, 80(6), 1339-1339.

74. Bekyarova, E.; Itkis, M. E.; Ramesh, P.; Berger, C.; Sprinkle, M.; de Herr, W. A.; Haddon, R. C. Chemical modification of epitaxial graphene: spontaneous grafting of aryl groups. Journal of the American Chemical Society 2009, 131(4), 1336-1337.

75. Avila-Vega, Y. I.; Leyva-Porras, C. C.; Mireles, M.; QuevedoLo'pez, M.; Macossay, J.; Bonilla-Cruz, J. Nitroxidefunctionalized graphene oxide from graphite oxide. Carbon 2013, 63, 376-389.

76. Bai, H.; Xu, Y.; Zhao, L.; Li, C.; Shi, G. Non-covalent functionalization of graphene sheets by sulfonated polyaniline. Chemical Communications 2009, 13, 1667-1669.
77. Salavagione, H. J.; Gomez, M. A.; Martınez, G. Polymeric modification of graphene through esterification of graphite oxide and poly(vinyl alcohol). Macromolecules 2009, 42, 6331-6334.

78. Matsuo, Y.; Tahara, K.; Sugie, Y. Structure and thermal properties of poly(ethylene oxide)-intercalated graphite oxide. Carbon 2007, 35, 113-120.

79. Zhao, X.; Zhang, Q.; Chen, D. Enhanced mechanical properties of graphene-based poly(vinyl alcohol) composites. Macromolecules 2010, 43, 2357-2363.

80. Zhang, H. B.; Zheng, W. G.; Yan, Q.; Yang, Y.; Wang, J.; Lu, Z. H.; Jia, G. Y.; Yu, Z. Z. Electrically conductive polyethylene terephthalate/graphene nanocomposites prepared by melt compounding. Polymer 2010, 51, 1191-1196.

81. Kalaitzidou, K.; Fukushima, H.; Drzal, L. T. Mechanical properties and morphological characterization of exfoliated graphite-polypropylene nanocomposites. Composites Part A: Applied Science and Manufacturing 2007, 38, 1675-1682.

82. Bianco, A.; Cheng, H. M.; Enoki, T.; Gogotsi, Y.; Hurt, R. H.; Koratkar, N.; Kyotani, T.; Monthioux, M.; Park, C. R.; Tascon, J. M. D.; Zhang, J. All in the graphene family - a recommended nomenclature for two-dimensional carbon materials. Carbon 2013, 65, 1-6.

83. Chatterjee, S.; Nafezarefi, F.; Tai, N. H.; Schlagenhauf, L.; Nuesch, F. A.; Chu, B. T. T. Size and synergy effects of nanofiller hybrids including graphene nanoplatelets and carbon nanotubes in mechanical properties of epoxy composites. Carbon 2012, 50, 5380-5386.

84. Wang, Z.; Xia, J.; Zhu, L.; Zhang, F.; Guo, X.; Li, Y.; Xia, Y. The fabrication of poly (acridine orange)/graphene modified electrode with electrolysis micelle disruption method for selective determination of uric acid. Sensors and Actuators B: Chemical 2012, 161, 131-136.

85. Zhu, W.; Low, T.; Perebeinos, V.; Bol, A. A.; Zhu, Y.; Yan, H.; Tersoff, J.; Avouris, P. Structure and electronic transport in graphene wrinkles. Nano Letters 2012, 12, 3431-3436.

86. Wang, Z.; Devel, M. Periodic ripples in suspended graphene. Physical Review B 2011, 83, 125422.

87. Schniepp, H. C.; Kudin, K. N.; Li, J-L.; Prud'Homme, R. K.; Car, R.; Saville, D. A.; Aksay, I. A. Bending properties of single functionalized graphene sheets probed by atomic force microscopy. ACS Nano 2008, 2(12), 2577-2584.

88. Shen, X.; Lin, X.; Yousefi, N.; Jia, J.; Kim, J. K. Wrinkling in graphene sheets and graphene oxide papers. Carbon 2013, DOI: http://dx.doi.org/10.1016/j.carbon.2013.08.046.

89. Zaman, I.; Phan, T. T.; Kuan, H. C.; Meng, Q.; La, L. T. B.; Luong, L.; Youssf, O.; Ma, J. Epoxy/graphene platelets nanocomposites with two levels of interface strength. Polymer 2011, 52, 1603-1611.

90. Lin, S. C.; Pearce, E. M. High-Performance Thermosets: Chemistry, Properties, Applications. Munich, Vienna, New York: Hanser Publishers, 1993. 
91. Wetzel, B.; Rosso, P.; Haupert, F.; Friedrich, K. Epoxy nanocomposites - fracture and toughening mechanisms. Engineering Fracture Mechanics 2006, 73, 2375-2398.

92. Blackman, B. R. K.; Kinloch, A. J.; Lee, J. S.; Taylor, A. C.; Agarwal, R.; Schueneman, G.; Sprenger, S. The fracture and fatigue behaviour of nano-modified epoxy polymers. Journal of Materials Science 2007, 42, 7049-7051.

93. Wang, K.; Chen, L.; Wu, J.; Toh, M. L.; He, C.; Yee, A. F. Epoxy nanocomposites with highly exfoliated clay: mechanical properties and fracture mechanisms. Macromolecules 2005, 38, 788-800.

94. Kim, B. C.; Park, S. W.; Lee, D. G. Fracture toughness of the nano-particle reinforced epoxy composite. Composite Structures 2008, 86, 69-77.

95. Gojny, F. H.; Wichmann, M. H. G.; Fiedler, B. K.; Schulte, K. Influence of different carbon nanotubes on the mechanical properties of epoxy matrix composites - a comparative study. Composites Science and Technology 2005, 65, 2300-2313.

96. Faber, K. T.; Evans, A. G. Crack deflection processes - I. Theory. Acta Metallurgica 1983, 31(4), 565-576.

97. Zhao, Q.; Hoa, S. V. Toughening mechanism of epoxy resins with micro/nano particles. Journal of Composite Materials 2007, 41, 201-219.

98. Park, S.; Lee, K. S.; Bozoklu, G.; Cai, W.; Nguyen, S. T.; Ruoff, R. S. Graphene oxide papers modified by divalent ions enhancing mechanical properties via chemical cross-linking. ACS Nano 2008, 2(3), 572-578.

99. An, Z.; Compton, O. C.; Putz, K. W.; Brinson, L. C.; Nguyen, S. T. Bio-inspired borate cross-linking in ultra-stiff graphene oxide thin films. Advanced Materials 2011, 23(33), 3842-3846.

\footnotetext{
WHAT DO YOU THINK?

To discuss this paper, please email up to 500 words to the managing editor at nme@icepublishing.com

Your contribution will be forwarded to the author(s) for a reply and, if considered appropriate by the editor-inchief, will be published as a discussion in a future issue of the journal.

ICE Science journals rely entirely on contributions sent in by professionals, academics and students coming from the field of materials science and engineering. Articles should be within 5000-7000 words long (short communications and opinion articles should be within 2000 words long), with adequate illustrations and references. To access our author guidelines and how to submit your paper, please refer to the journal website at www.icevirtuallibrary.com/nme
} 